- Dr. Alan W. Wilhite

\title{
Estimating the Risk of Technology Development
}

Dr. Alan W. Wilhite

Langley Distinguished Professor/Systems Architectures and Analysis

Georgia Institute of Technology/National Institute of Aerospace

256.683.2897

\section{When do you do risk analysis?}

Risk analysis and response planning must be done during the initial planning phase of the project. Ideally, risk analysis and response planning is done during the project proposal phase and revisited on a regular basis.

"70\% of a project's cost at completion is committed by the time the first $5 \%$ of the project's budget is actually spent." 


\section{The Elements of Risk}

Risk is composed of TWO elements:

1.) The UNCERTAINTY (expressed as a probability (Pf) of achieving a project performance objective

AND,

2.) The CONSEQUENCES (Cf) of a risk event

\section{Risk= Pf $\times$ Cf}

Caution is needed, of course in using this approach. It is necessary to be wary of multiplying 2 pieces of information together to produce a figure which may, make an account's eyes light up but be of little practical value to a project manager.

\section{Risk Assessment Matrix}

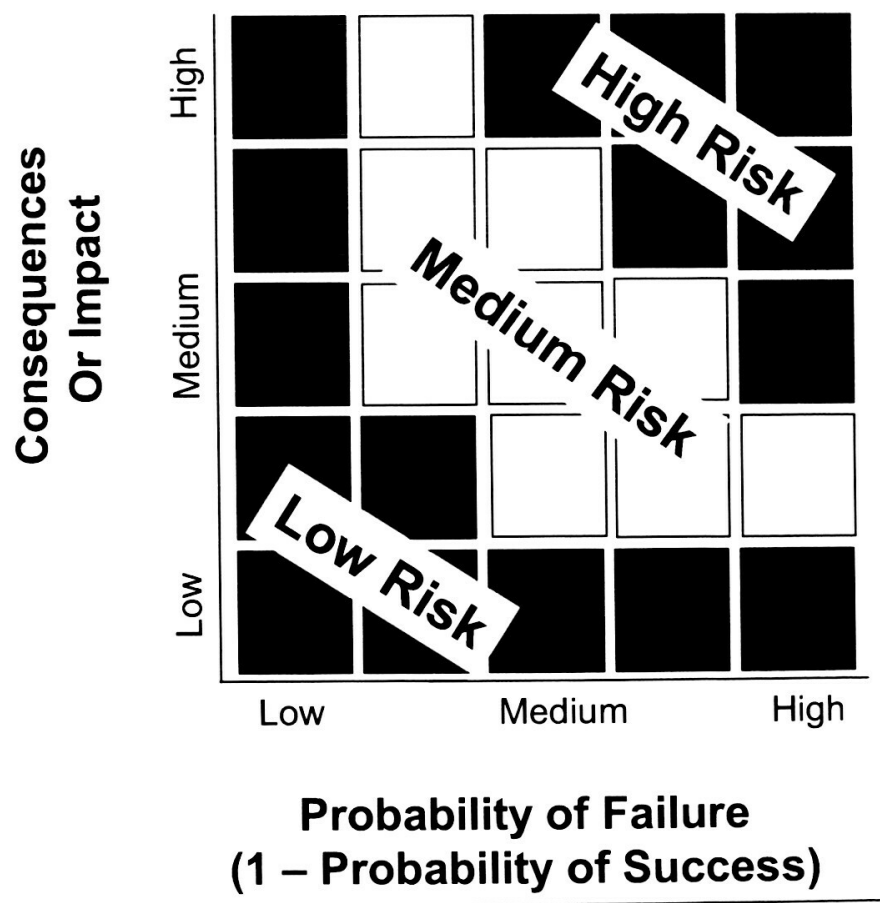




\section{Characterization of Technology Risk}

(utilization for system development)

- Probability of failure to:

- Reach maturity for system integration (programmatic failure)

- And meet Technical Performance Measures goals (technical failure)

- Impact on overall system performance of failing to meet TPM goals

\section{Measures of Probability of Failure}

- The Probability of Failure is measured by the three measures used for programs or projects - cost, schedule, and performance.

Performance (technical failure)

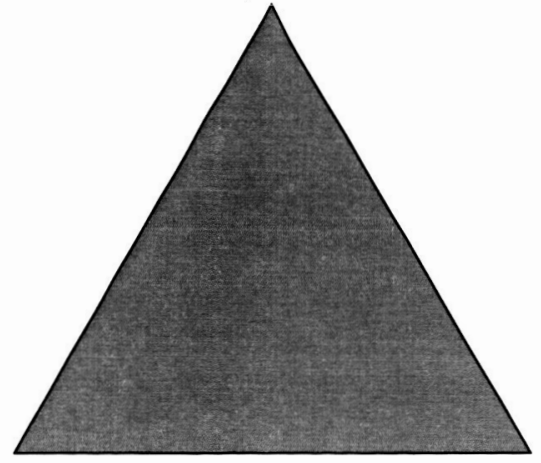

Cost

Schedule (programmatic failure) 


\section{Measures of Programmatic Failure}

- Development difficulty

- Technology Readiness Level Gap (Initial to TRL6)

- Research and Development Degree of Difficulty

- TPM gap

- Requirements, requirements flowdown, interface requirements, etc.

- Schedule

- Defined schedule showing maturity increasing/adequate analysis and testing

- Critical Path

- Adequate slack

- High risk items, work around

- Exit criteria for every milestone

- Cost

- Defined cost for all milestones

- Costs include NASA and contractor

- Management and technical team (experienced)

\section{NASA's TECHNOLOGY READINESS LEVEL (Scale for Tracking Risk Reduction)}

9 - Actual system "flight proven" on operational flight

8 - Actual system completed and "flight qualified" through test and demonstration

7 - System prototype demonstrated in flight

6 - System/Subsystem (configuration) model or prototype demonstrated/validation in a relevant environment

5 - Component (or breadboard) verification in a relevant environment

4 - Component and/or breadboard test in a laboratory environment

3 - Analytical \& experimental critical function, or characteristic proof-of-concept, or completed design

2 - Technology concept and/or application formulated (candidate selected)

1 - Basic principles observed and reported

Technology Readiness Level of 6 is usually required for Development 


\section{NASA's \\ Technology Readiness Levels (Software)}

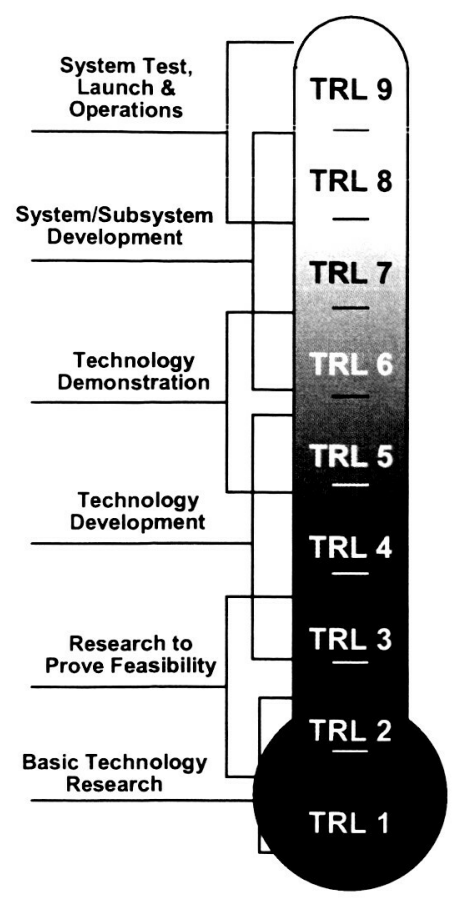

TRL 9: Actual system "mission proven" through successful mission operations Thoroughly debugged software readily repeatable. Fully integrated with operational hardware/software systems. All documentation completed. Successful operational experience. Sustaining software engineering support in place. Actual system fully demonstrated

TRL 8: Actual system completed and "mission qualified" through test and demonstration in an operational environment Thoroughly debugged software. Fully integrated with operational hardware and software systems. Most user documentation, training documentation, and maintenance documentation completed. All functionality tested in simulated and operational scenarios. V\&V completed.

TRL 7: Initial system demonstration in high-fidelity environment (parallel or shadow mode operation) Most functionality available for demonstration and test. Well integrated with operational hardware/software systems. Most software bugs removed. Limited documentation available.

TRL 6: System/subsystem prototype validated in a relevant end-to-end environment Prototype implementations on full scale realistic problems. Partially integrated with existing hardware/software systems. Limited documentation available. Engineering feasibility fully demonstrated.

TRL 5: Module and/or subsystem qualified in relevant environment Prototype implementations conform to target environment/interfaces. Experiments with realistic problems. Simulated interfaces to existing systems

TRL 4: Module and/or subsystem qualified in laboratory environment Standalone prototype implementations. Experiments with full scale problems or data sets.

TRL 3: Analytical and experimental critical function and/or characteristic proofof-concept Limited functionality implementations. Experiments with small representative data sets Scientific feasibility fully demonstrated.

TRL 2: Technology concept and/or application formulated Basic principles coded. Experiments with synthetic data. Mostly applied research.

TRL 1: Basic principles observed and reported Basic properties of algorithms, representations \& concepts. Mathematical formulations. Mix of basic and applied research.

\section{Measures of Programmatic Failure}

- Development difficulty

- Technology Readiness Level Gap (Initial to TRL6)

- Research and Development Degree of Difficulty

- TPM gap

- Requirements, requirements flowdown, interface requirements, etc.

- Schedule

- Defined schedule showing maturity increasing/adequate analysis and testing

- Critical Path

- Adequate slack

- High risk items, work around

- Exit criteria for every milestone

- Cost

- Defined cost for all milestones

- Costs include NASA and contractor

- Management and technical team (experienced) 


\section{Research and Development \\ Degree of Difficulty $\left(R^{3}{ }^{3}\right)$}

\section{${\underline{R} \& \mathbf{D}^{3}}^{3}$}

I A very low degree of difficulty is anticipated in achieving research and development objectives for this technology.

Probability of Success in "Normal" R\&D Effort $>99 \%$

II A moderate degree of difficulty should be anticipated in achieving R\&D objectives for this technology.

Probability of Success in "Normal" R\&D Effort $>90 \%$

III A high degree of difficulty anticipated in achieving R\&D objectives for this technology.

Probability of Success in "Normal" R\&D Effort $>80 \%$

IV A very high degree of difficulty anticipated in achieving R\&D objectives for this technology.

Probability of Success in "Normal" R\&D Effort $>50 \%$

V The degree of difficulty anticipated in achieving R\&D objectives for this technology is so high that a fundamental breakthrough is required.

Probability of Success in "Normal" R\&D Effort $>20 \%$

\section{Measures of Programmatic Failure}

- Development difficulty

- Technology Readiness Level Gap (Initial to TRL6)

- Research and Development Degree of Difficulty

- TPM gap

- Requirements, requirements flowdown, interface requirements, etc.

- Schedule

- Defined schedule showing maturity increasing/adequate analysis and testing

- Critical Path

- Adequate slack

- High risk items, work around

- Exit criteria for every milestone

- Cost

- Defined cost for all milestones

- Costs include NASA and contractor

- Management and technical team (experienced) 


\section{NASA Program Schedule Actuals}

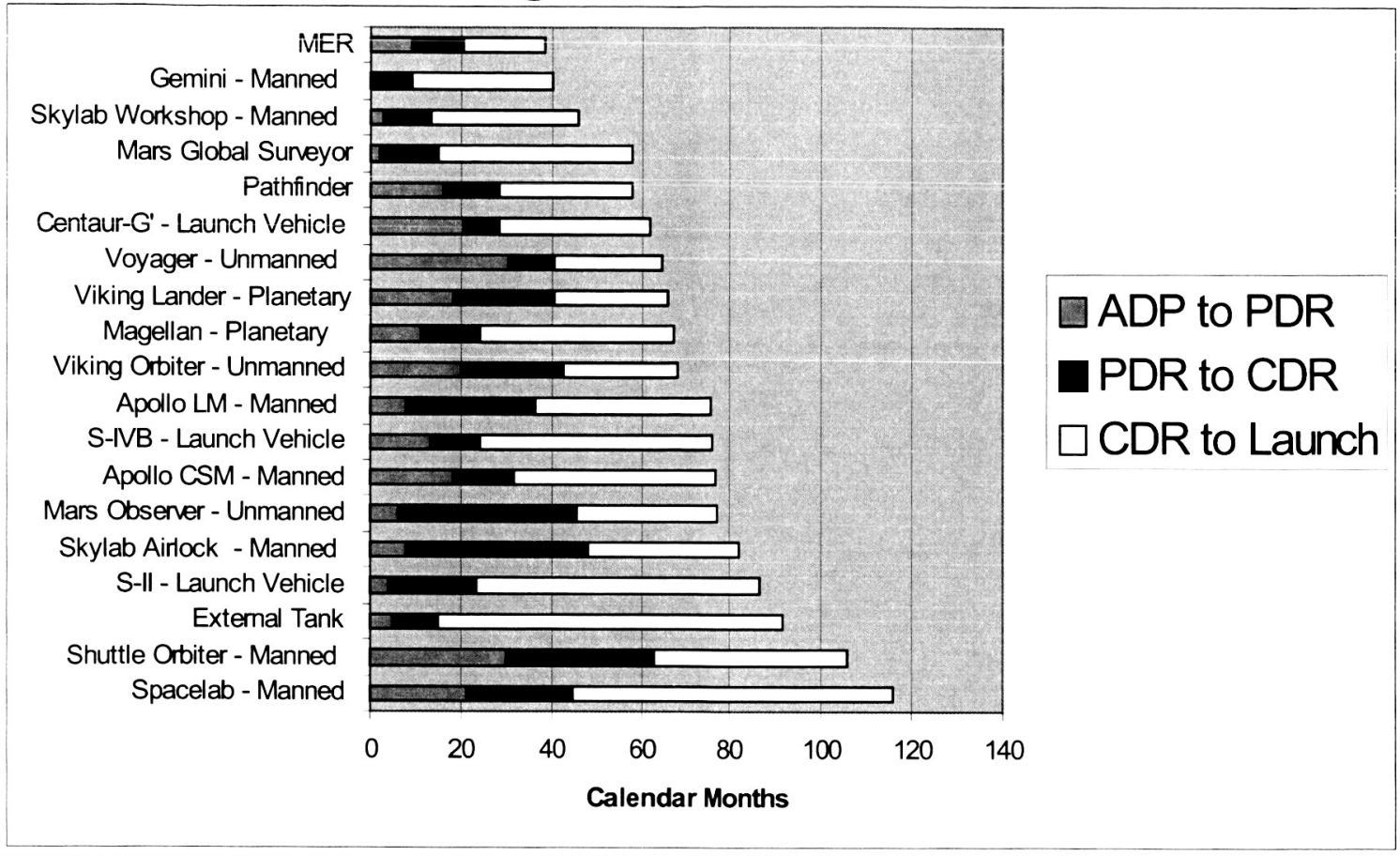

\section{Life Cycle Milestones}

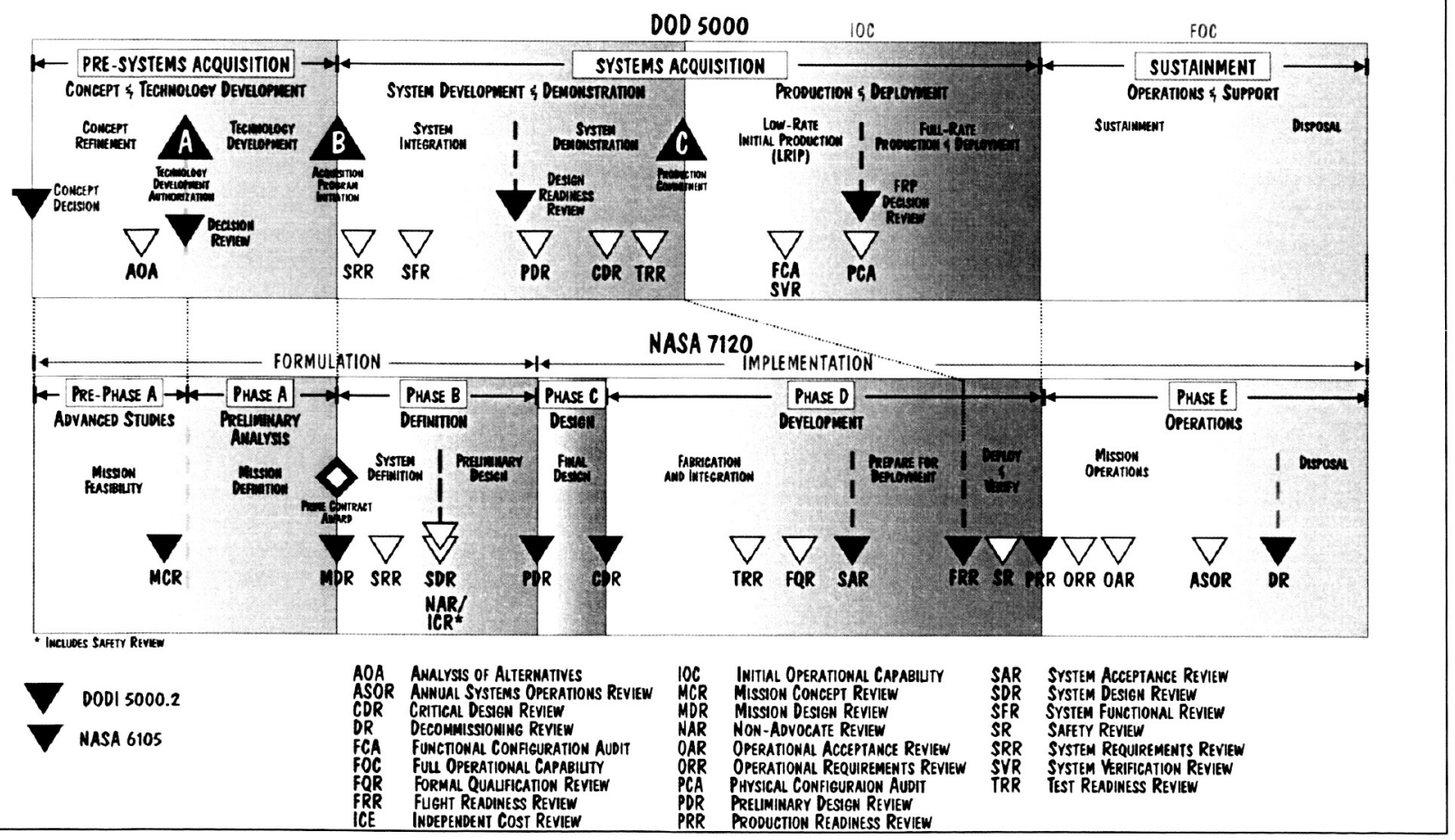




\section{Measures of Programmatic Failure}

- Development difficulty

- Technology Readiness Level Gap (Initial to TRL6)

- Research and Development Degree of Difficulty

- TPM gap

- Requirements, requirements flowdown, interface requirements, etc.

- Schedule

- Defined schedule showing maturity increasing/adequate analysis and testing

- Critical Path

- Adequate slack

- High risk items, work around

- Exit criteria for every milestone

- Cost

- Defined cost for all milestones

- Basis of costs (FTEs, facilities, hardware, etc.)

- Management and technical team (experienced)

\section{Low NOx Combustor}

\section{1-Pager Work Logic}

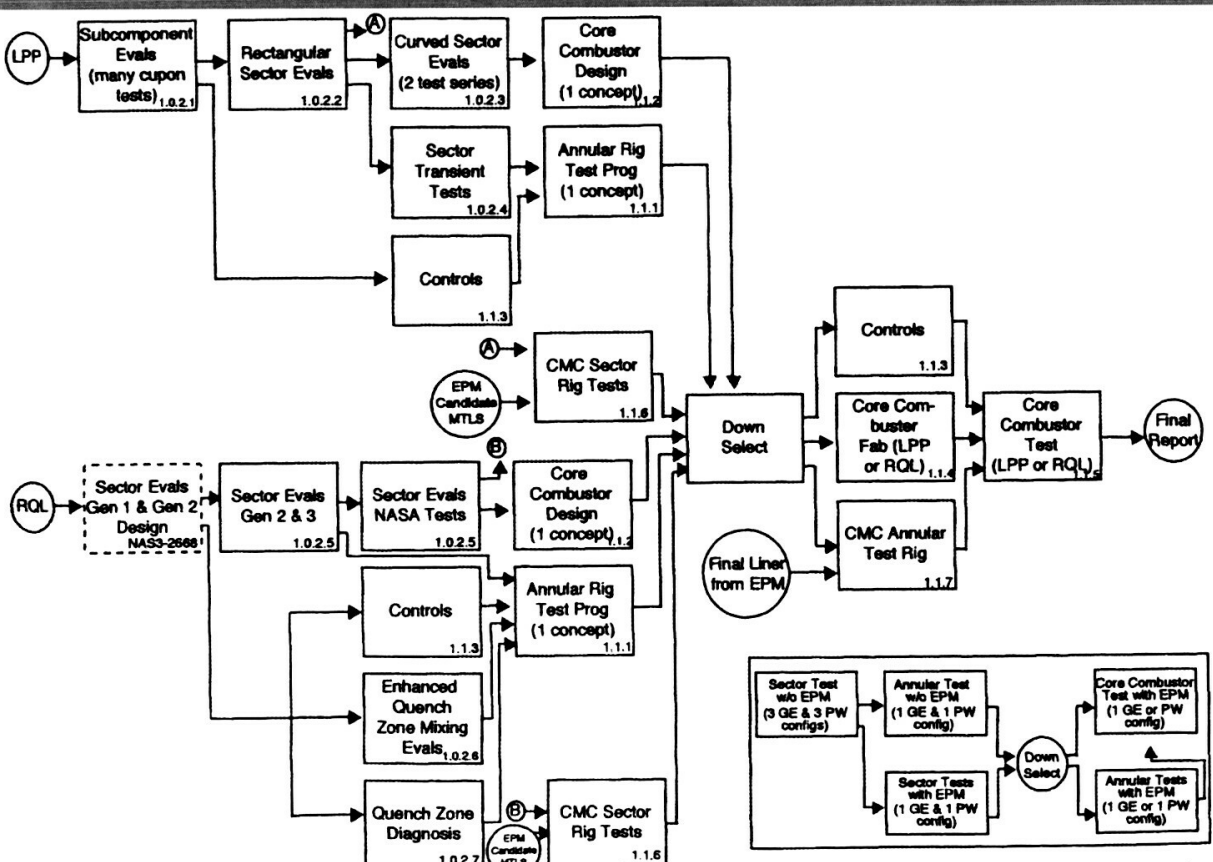




\section{Low NOx Combustor}

\section{1-Pager Work Logic Description}

10.2.1 LPP Subcomponent Evals

- Many cupons tested

- Feeds sector test prog

- Continues during sector test prog

- Used for sector design refinement

- Essentially complete by FY95

- GENASA

\subsubsection{CPPRectanpular Sector Evals}

- Combines components for integrated evals

- 3 configurations tested

- Primary feed to annular test program design

- Secondary feed to core combustor test program design

- Uses non EPM materials

- GE/NASA

1.0.2.3 LPP Curved Sector Evaluation

- Added shape fidelity over rectangular evals

- Two test series of single configuration

- Feed core combustor test program design

- GE

10.2.4 LPP Sector Transient Test

- Evaluation of rectangular sector configurations

- Primary feed to annular test program design
1.0.2.5 ROL Sector Combustion Rig

- 3 generation tests of progressively complex design

- Gen I tests and Gen II design from separate contract

- P\&W test feed annular rig test program design

- NASA test feed core combustor test program

- Uses non EPM materials

- P\&W/NASA

1.0.2.6 Inhanced Quench Zone Mixing

- Applies to RQL configuration

- P\&W/NASA participation

- Feeds annular rig test program design

1.0.2.7 Quench Zone Diagonistics

- Same as 1.0.2.6

- P\&W participation

1.0.2.8 Analytical Code Dev

- Feed products to test programs as developed

- NASA

1.0.2.9 Emission Minimizing Completion Controls

- Feed products to test programs as developed - NASA

1.0.2.10 Grants

- Feed products to test programs as developed

- Universities

\section{Low NOx Combustor}

\section{1-Pager Work Schedule}

\begin{tabular}{|c|c|c|c|c|c|c|c|c|c|c|c|}
\hline & & & & CY95 & CY96 & CY97 & CY98 & CY99 & CYOO & CY01 & \\
\hline & & & & FY95 & FY96 & FY97 & FY98 & FY99 & FYOO & FYO1 & \\
\hline & & & & $1: 2: 3: 4$ & $1 \vdots 2 \vdots 3 \vdots 4$ & $1: 2 \vdots 3 \vdots 4$ & $1 \vdots 2 \vdots 3: 4$ & $1 \div 2 \vdots 3: 4$ & $1: 2 \vdots 3: 4$ & $1: 2: 3: 4$ & \\
\hline LPP & 1.022 & 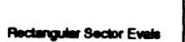 & $\boldsymbol{Q} E$ & $\begin{array}{l}\vdots 1 \\
\vdots\end{array}$ & $\nabla^{3 \vdots}$ (3 Conouplas) & $\bar{\nabla}$ & Donimatiot & & & Find Repon V & \\
\hline & & 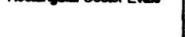 & & a & 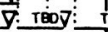 & $80 \dot{y}$ & & & & & \\
\hline & 1.0 .2 .4 & 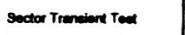 & QEPW & & & & & & & & \\
\hline & 1.0 .2 .3 & Curved Sector Evere & GE & & $8: \nabla$ & & & & & & \\
\hline & 1.1.3 & Controle & OE & $\vdots \quad \vdots$ & $\nabla_{\text {Anner }}$ & $\nabla$ cono & & & & & \\
\hline & 1.1 .1 & Amierer Fiag Teat Prog & & 0 & $\vdots$ FA & $\tau: \nabla \stackrel{1}{\top} \mathrm{co}$ & copix) & & $:$ & $\vdots$ & \\
\hline & $\begin{array}{l}1.1 .2 \\
1.1 .6\end{array}$ & Core combutor Dosolon & OE & & & \begin{tabular}{l}
$\vdots$ \\
$\vdots$ \\
$\vdots$ \\
\hdashline
\end{tabular} & بَ & $\vdots$ & 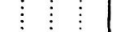 & $\vdots$ & \\
\hline AOA & t.0.2.5 & Soctor Evertaen 283 & Pw & $\vdots \vdots \vdots 2$ & & & & & $\vdots$ & : & \\
\hline & & & & i & r & $\dot{\nabla}$ & & & & & \\
\hline & $\begin{array}{l}1.0 .2 .67 n \\
1.1 .3\end{array}$ & $\begin{array}{l}\text { Ouench Zono Everis } \\
\text { Conterole }\end{array}$ & & $\dot{\vdots}$ & $\nabla \mathrm{Am}$ & $\nabla$ core & & & $\vdots$ & 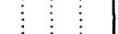 & \\
\hline & 1.1 .1 & Aroucler forg Tou Prog & PW & $\dot{\varphi}$ & EA & $\nabla(1 \mathrm{co}$ & coppi) & & $\vdots$ & & \\
\hline & 1.1 .2 & Cone Combenter Doulgn & Pw & $\vdots$ & & $0 \div$ & & & $\vdots$ & & \\
\hline & 1.1.6 & CMC Sector Pho Tats & QEPW & & EA & קיنـ & & & : & $\vdots \vdots$ & \\
\hline LPP or ROL. & 1.1.45 & core comouner & QEPW & & & & & 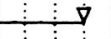 & $i$ & $\stackrel{\square}{\longrightarrow}$ & \\
\hline & 1.1 .7 & CNC Amoner Tout Alo & & & & & + & -1 & 界: & $:$ & \\
\hline & 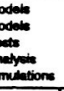 & 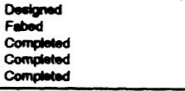 & & $\begin{array}{r}11 \\
7 \\
7 \\
4 \\
7\end{array}$ & $\begin{array}{r}2 \\
7 \\
12 \\
13 \\
4 \\
\end{array}$ & $\begin{array}{r}2 \\
0 \\
10 \\
1 \\
\end{array}$ & & & & & \\
\hline & $\begin{array}{l}1.0 .2 \\
1.1 .1 \\
1.1 .2 \\
1.1 .3 \\
1.1 .4 \\
1.1 .5 \\
1.1 .8 \\
1.1 .7\end{array}$ & 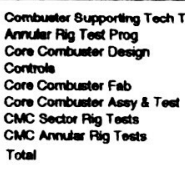 & & $\begin{array}{r}9.4 \\
7.1 \\
1.4 \\
.3 \\
18.6\end{array}$ & $\begin{array}{r}6.0 \\
9.5 \\
.4 .5 \\
1.1 \\
\\
.9 \\
.3 \\
22.3\end{array}$ & $\begin{array}{r}1.7 \\
\frac{.9}{13.0}\end{array}$ & $\begin{array}{l}1.2 \\
1.8 \\
.7 \\
.6 \\
.6 \\
.7 \\
5.5\end{array}$ & $\begin{array}{r}1.1 \\
.9 \\
1.0 \\
2.8 \\
1.2 \\
2.8 \\
9.8\end{array}$ & $\begin{array}{r}.1 \\
.7 \\
.5 \\
.5 \\
1.2 \\
1.5 \\
10.9\end{array}$ & $\begin{array}{r}.5 \\
.3 \\
4.5 \\
.1 \\
5.4\end{array}$ & $\begin{array}{r}19.8 \\
18.5 \\
14.5 \\
66.3 \\
3.8 \\
13.5 \\
3.0 \\
6.3 \\
65.7\end{array}$ \\
\hline
\end{tabular}




\section{Low NOx Combustor}

\section{1-Pager Cost Distribution}

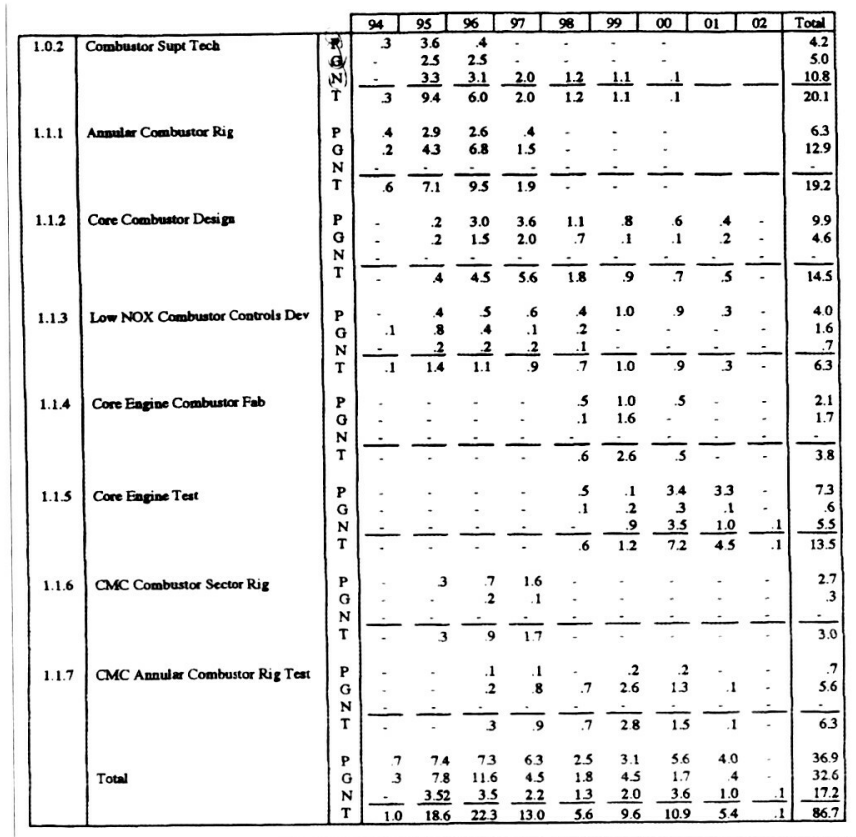

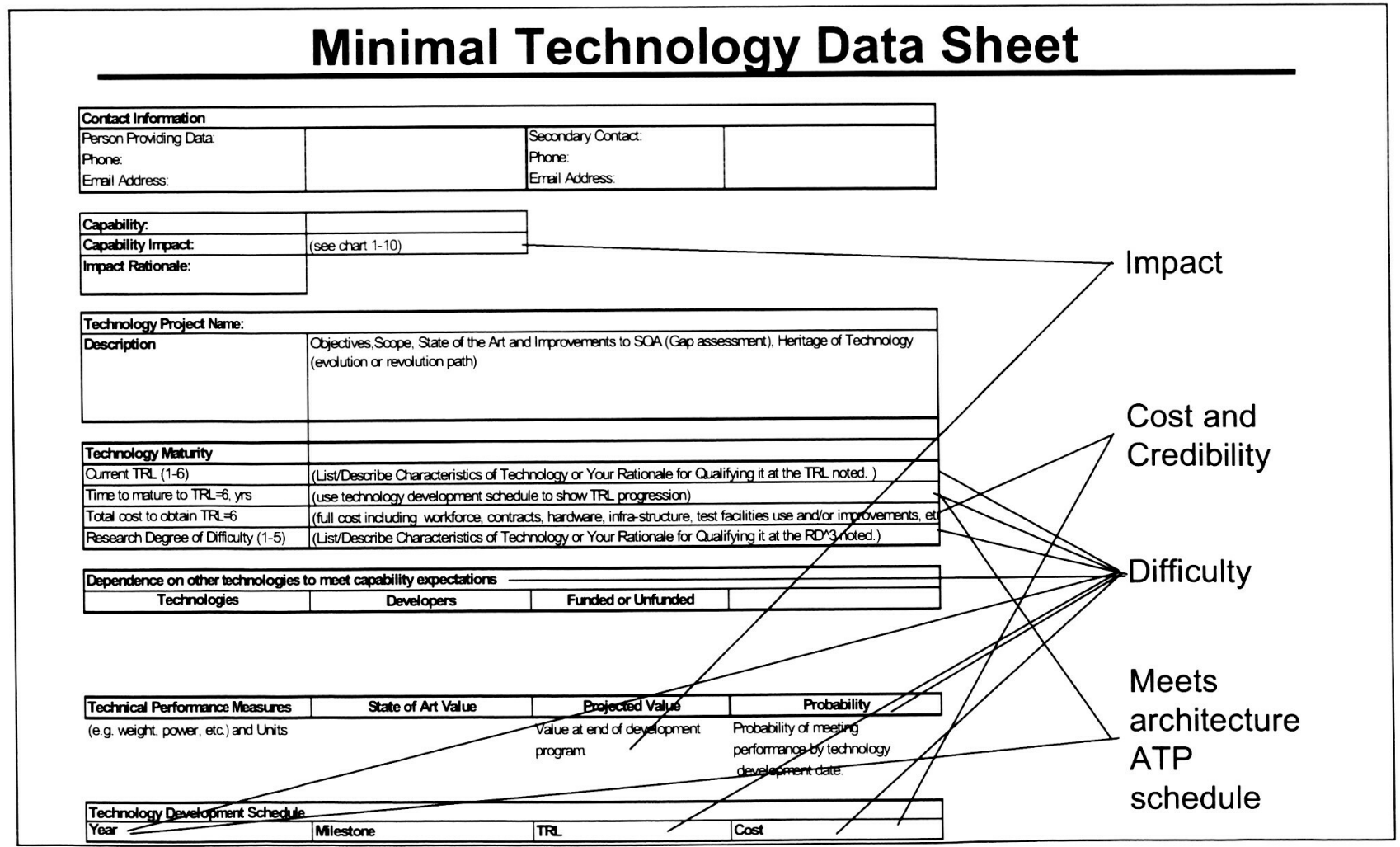




\section{Assessing Technology Risk Using AHP (Analytical Hierarchical Process)}

- The AHP is based on the hierarchical decomposition of the prioritization or forecasting criteria down to the level at which the decision or forecast alternatives can be pairwise compared for relative strength against the criteria.

- The pair-wise comparisons are made by the participating experts and translated onto a numerical ratio scale.

- The AHP mathematical model then uses the input pair-wise comparisons data to compute priorities or forecast distributions as appropriate.

\section{Analytical Hierarchical Process}

\section{Individual Assessment}

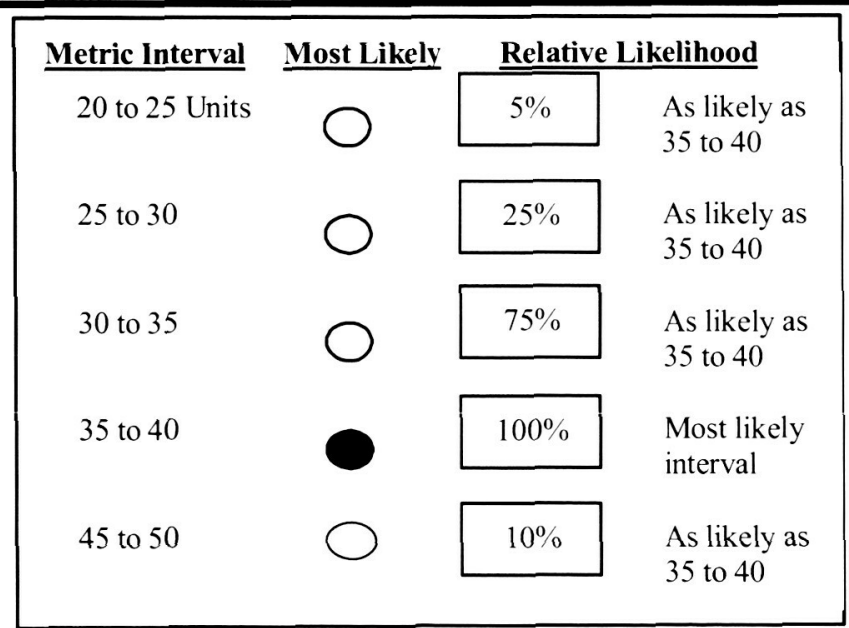

Integrated Group Assessment

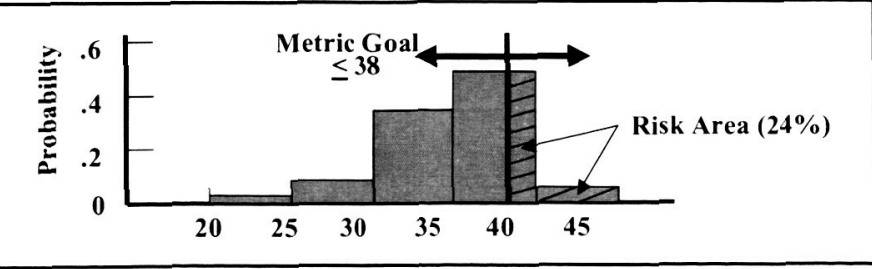




\section{Technology Risk Assessment - Phase 3 Summary Of Airframe Risk Assessments}

\begin{tabular}{|c|l|c|c|c|}
\hline TA & \multicolumn{1}{|c|}{ TECHNOLOGY PROJECT } & COST & SCHED & TECH \\
\hline 2 & STRUCTURAL HEALTH MONITORING - NORTHROP GRUMMAN & & & \\
\hline 2 & METALLIC CRYOTANK - BOEING & & \\
\hline 2 & CERAMIC MATRIX HOT STRUCTURES - MRD & & \\
\hline 2 & DURABLE ACREAGE CERAMIC TPS - BOEING & & \\
\hline 2 & DURABLE ACREAGE METALLIC TPS - OCEANEERING & & \\
\hline 2 & $\begin{array}{l}\text { INTEGRATED AERO-THERMAL \& STRUCTURAL THERMAL } \\
\text { ANALYSIS - NASA }\end{array}$ & & No Data & \\
\hline 2 & STRUCTURAL \& MATERIALS/TANK/TPS INTEGRATION - NASA & & \\
\hline 2 & STAGE SEP \& ASCENT AERO-THERMODYNAMICS - NASA & & \\
\hline 2 & $\begin{array}{l}\text { MATERIALS \& ADVANCED MANUFACTURING: PERMEABILITY } \\
\text { RESIST ANCE - NASA }\end{array}$ & & \\
\hline 2 & $\begin{array}{l}\text { LIGHTWEIGHT INFORMED MICRO-METEOROID RESISTANT } \\
\text { TPS - NASA }\end{array}$ & & \\
\hline 2 & ULTRA HIGH TEMPERATURE SHARP EDGE TPS - LMC & & \\
\hline 2 & CERAMIC MATRIX COMPOSITE - SOUTHERN RESEARCH & & \\
\hline
\end{tabular}

\section{Technology Risk Assessment - Phase 3 Structural Health Monitoring (Shm)}

\section{TA-2 Airframe}

\section{MAJOR RISKS}

Northrop Grumman

Cost - Cost of 8,000 sensors for full scale SHM could be very high, but is understood.

Schedule - Critical schedule issue is availability of Composite Cryo-tank for testing. SHM starting at TRL 4 in 2002. No development issues affecting schedule.

Technical

$>$ Reliability - Integration of 8,000 sensors into one reliable SHM is a risk

$>$ Testability - Availability of Full Scale Composite Cryo-tank for testing to achieve TRL 6

\section{CONTINGENCY PLAN SUGGESTION}

Use a subscale tank ( 18 to $20 \mathrm{ft}$ diameter) to test SHM system

NOTE: Only new or updated comments are contained in this report. Refer to Phase 2 report for complete evaluation. No significant change in evaluation from Phase 2.

\section{Show Stopper - Lack of Funding for Composite Cryo-tank for Testing}

NOTICE: This information is technical data within the definition of the International Traffic in Arms regulation (ITAR) and or Export Control Administration Regulations (EAR) and is subject to the
export control laws of the United States. Transfer of this data by any means to unauthorized persons, as defined by these laws, whether in the U. S. or abroad, without an export license or other approval from the U.S. Department of State is expressly probihited.
for 


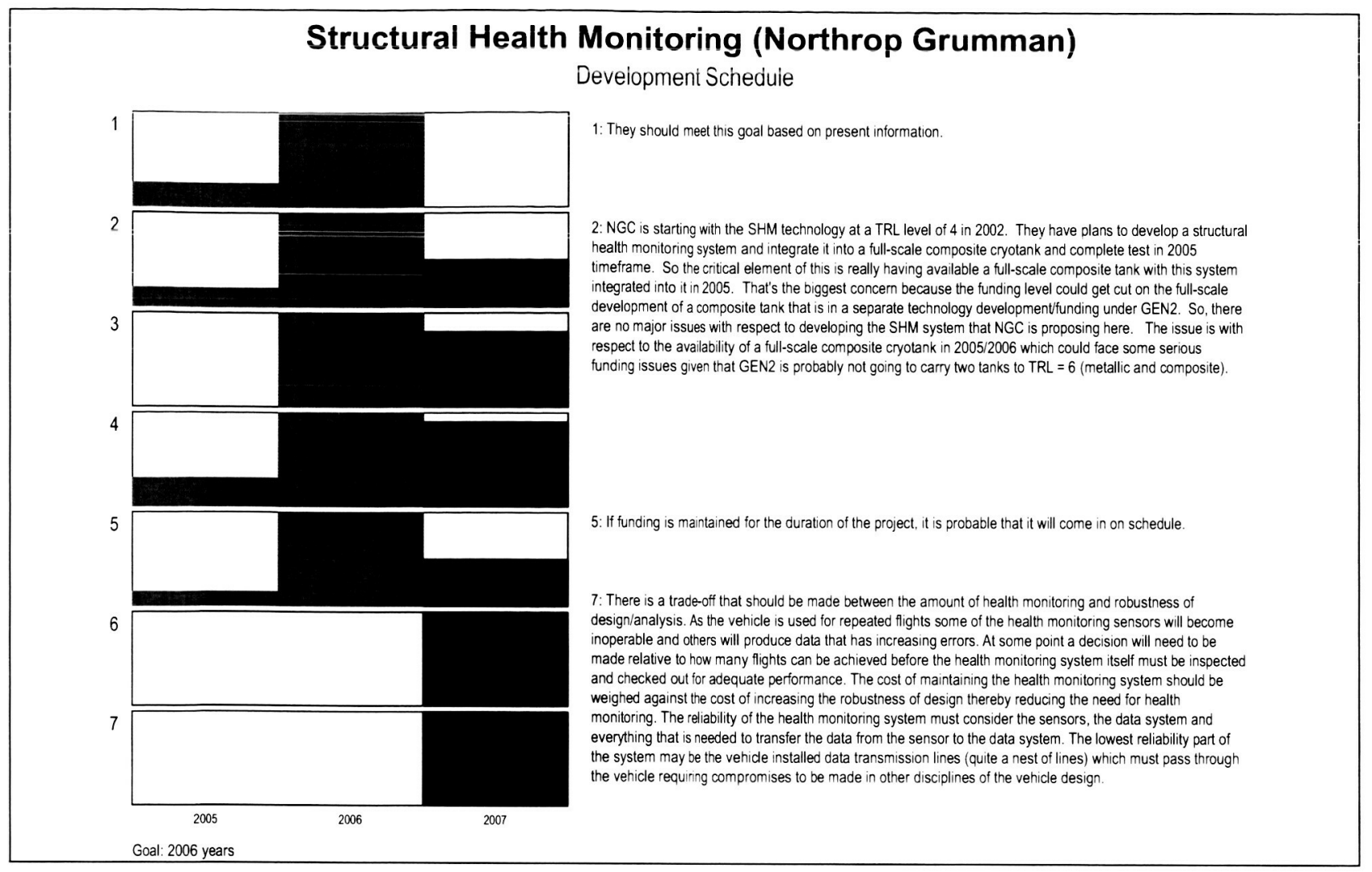

\section{Technology Success Data}

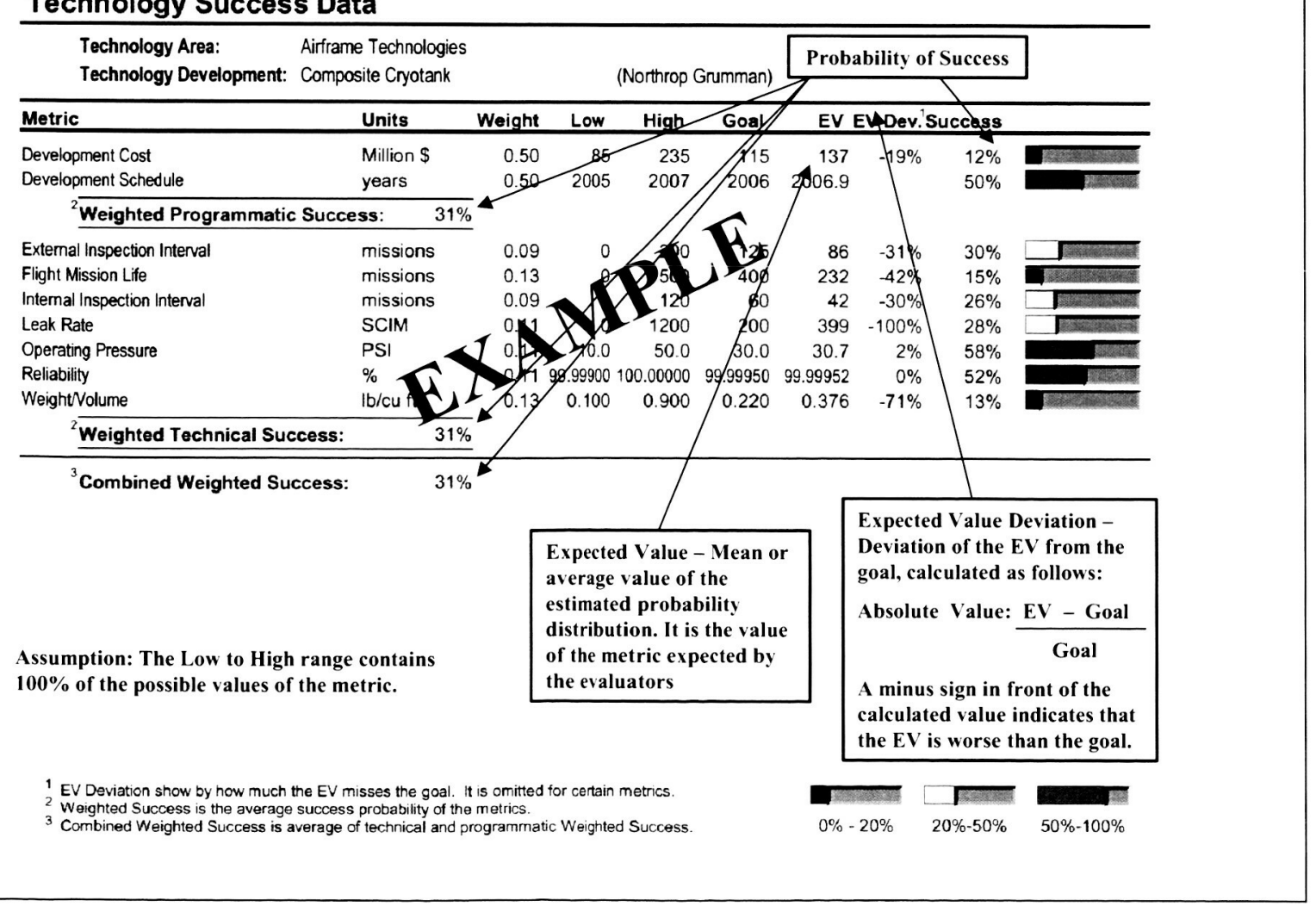




\section{Risk Assessment Matrix}

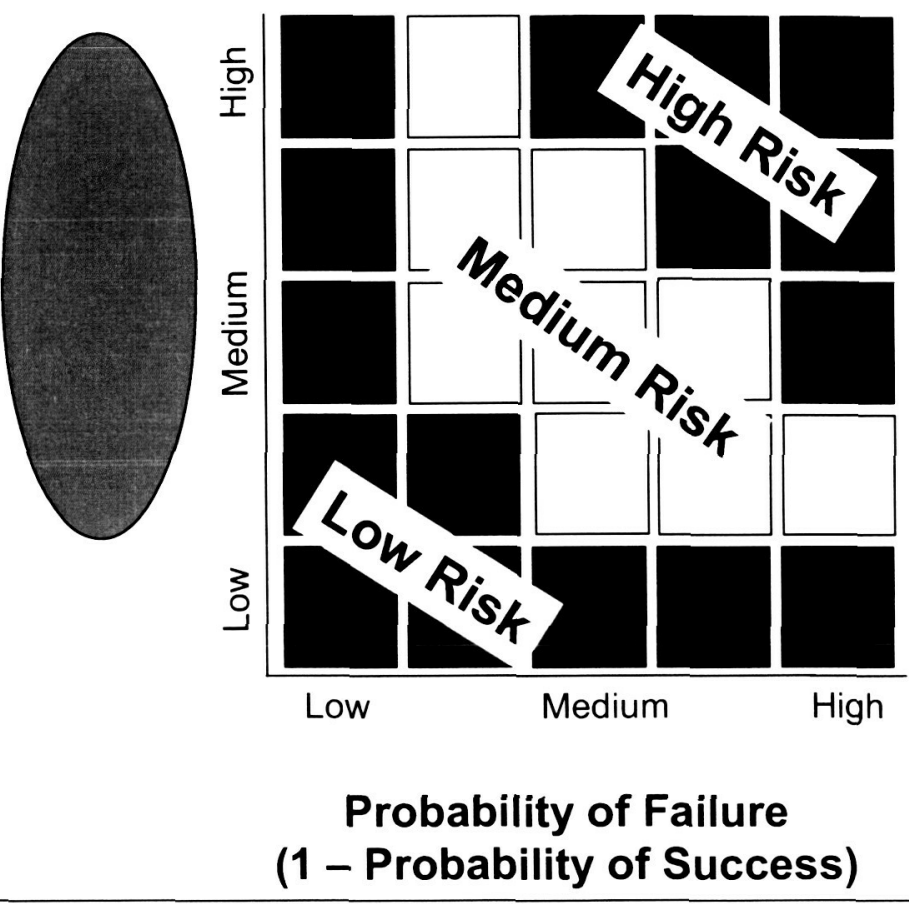

\section{Launch Vehicle Propulsion Technology Selection}

\begin{tabular}{|l|r|r|r|r|r|r|}
\hline & $\begin{array}{r}\text { Delta Isp; } \\
\text { see }\end{array}$ & Cost & $\begin{array}{r}\text { Delta } \\
\text { Isp/Cost }\end{array}$ & RD'3 & $\begin{array}{r}\text { Probability } \\
\text { of Failure }\end{array}$ \\
\hline Metalized Hydrogen & 15 & 200 & 0.075 & 2 & 5 & 25 \\
\hline Advanoed Materials & 10 & 150 & 0.067 & 3 & 4 & 16 \\
\hline Chamber Pressure & 8 & 100 & 0.080 & 3 & 4 & 16 \\
\hline Combustion Efficiency & 6 & 90 & 0.067 & 4 & 3 & 9 \\
\hline NozzleEficiency & 4 & 50 & 0.080 & 4 & 2 & 6 \\
\hline OFF Ratio & 2 & 65 & 0.031 & 5 & 2 & 4 \\
\hline
\end{tabular}

What is the your investment order? 


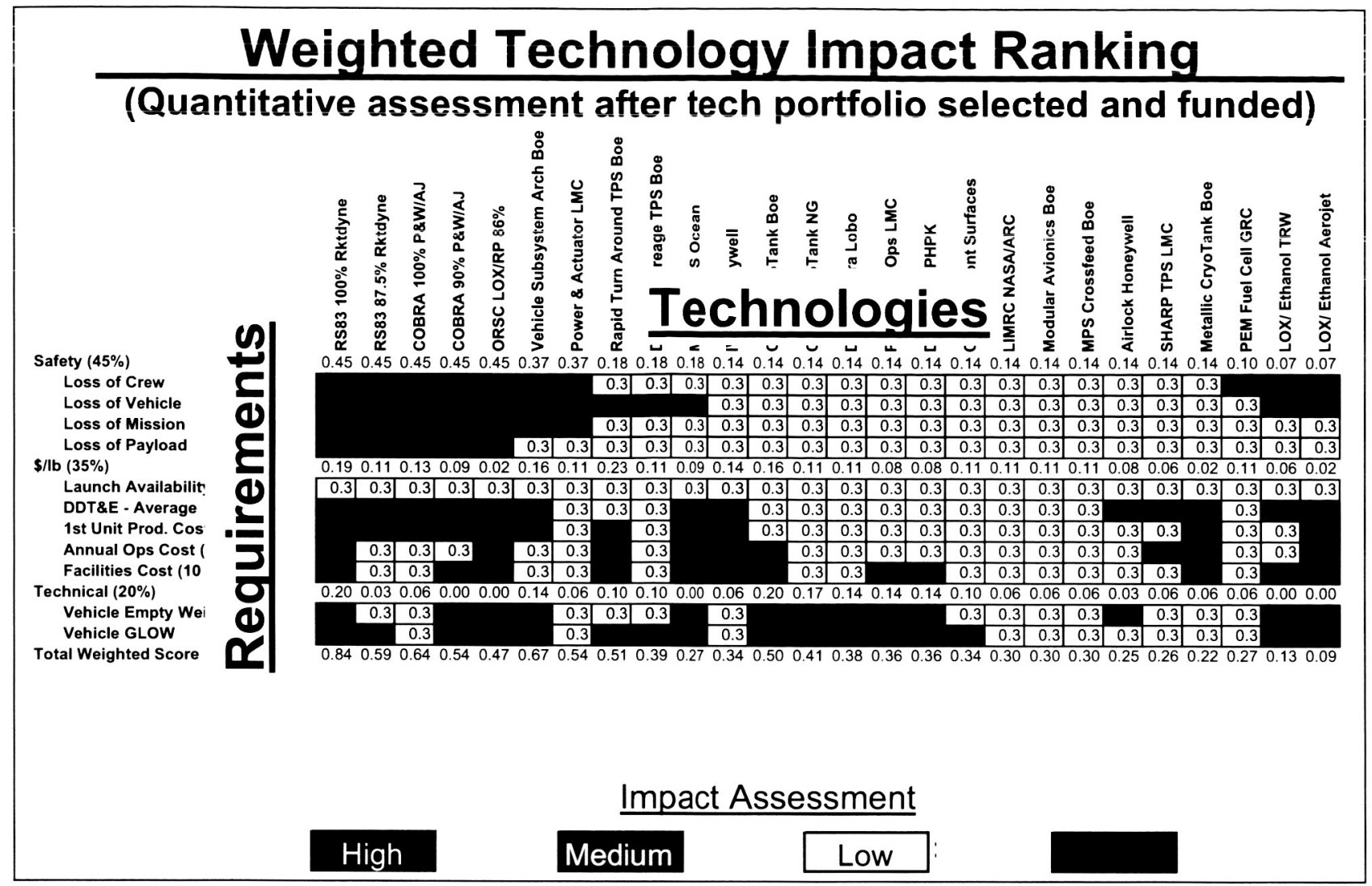

\section{Comments on Investment Strategy and Impact Assessment Method}

- Very poor choice of technology portfolio ( two-thirds of technologies have low or negative impact)

- Wrong requirements were developed

- Systems analysis did not model the technologies correctly 


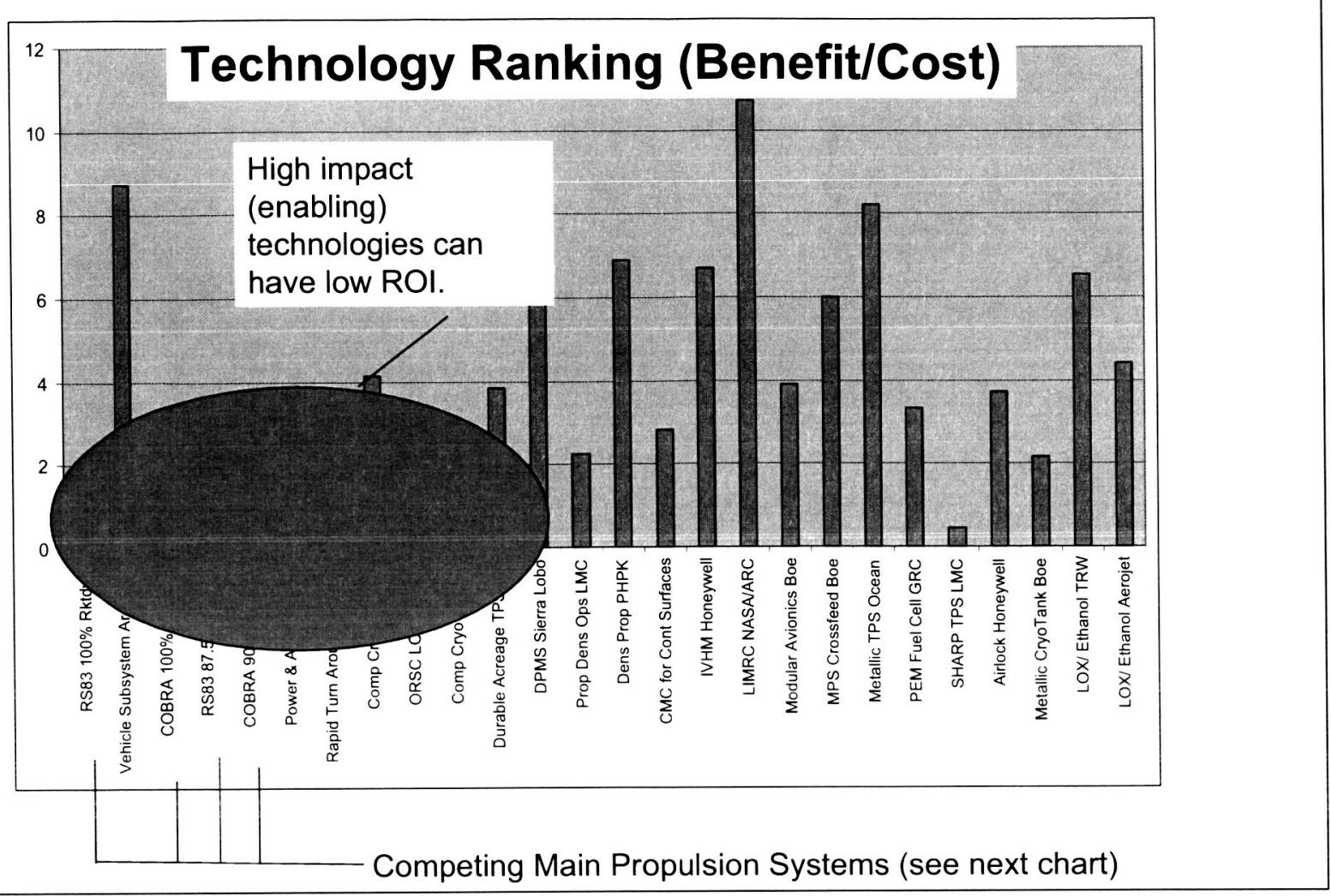

\section{Technology Risk Assessment}

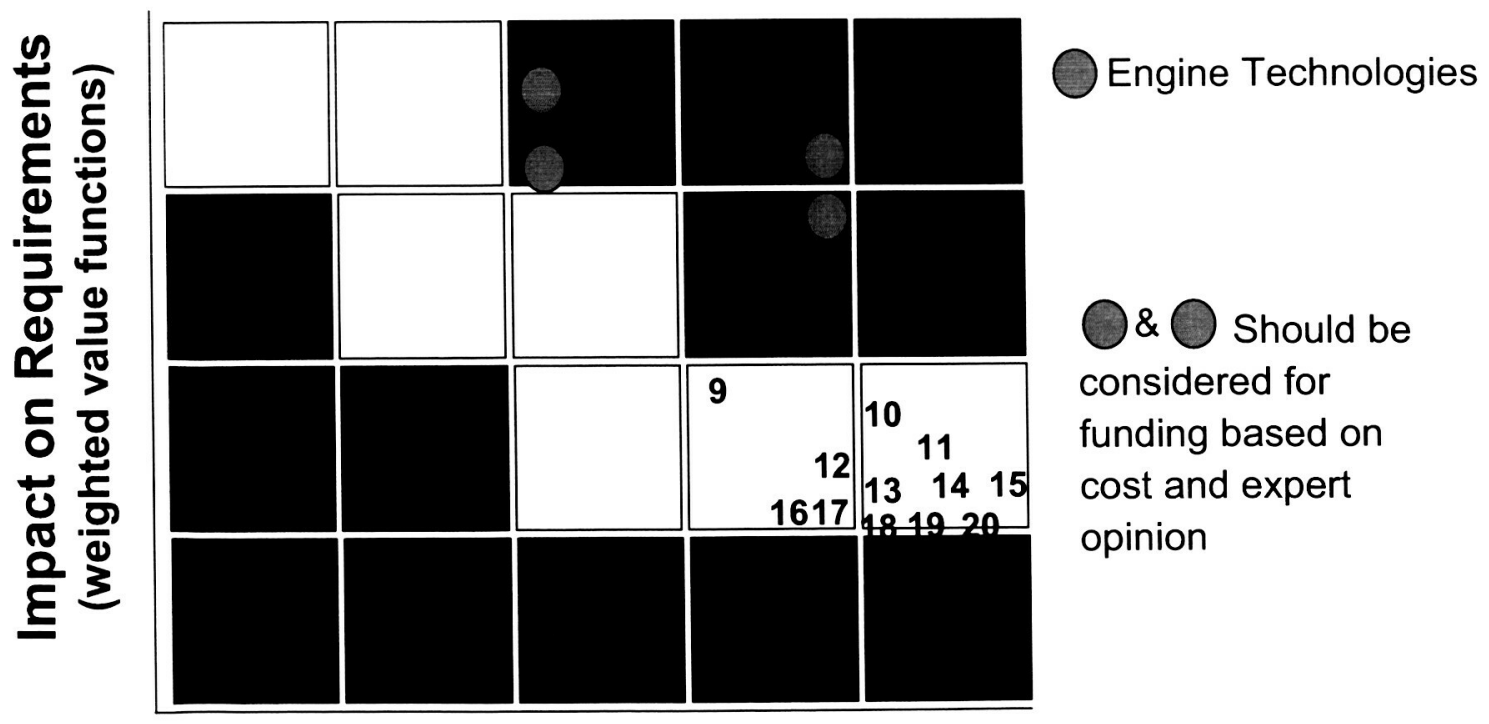

Probability of Failure (TRL, RD^3, Cost, Schedule) 


\section{Technology Agency Impact Model}

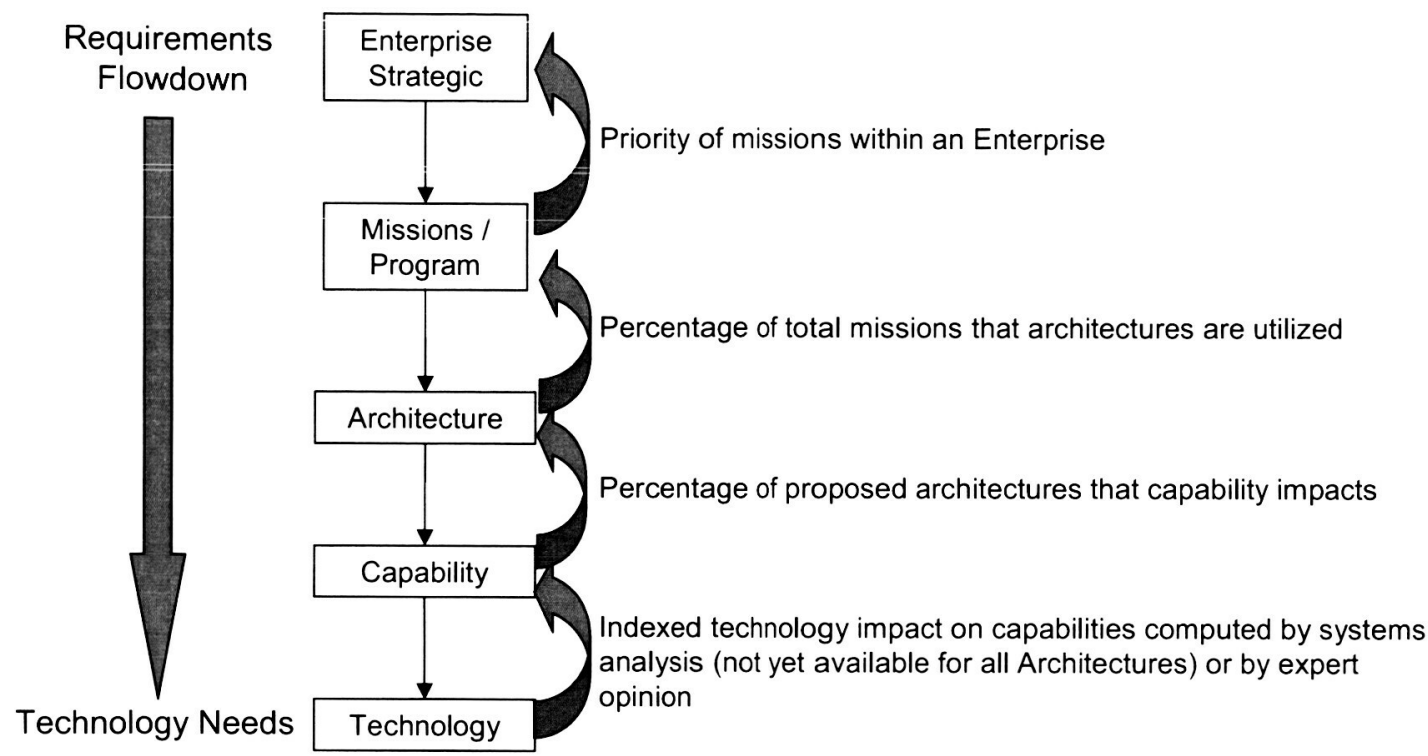

Technology = Capability . Architecture * Mission * Enterprise Impact Impact Impact Impact Impact

\section{Summary Technology Risk Assessment}

- Technology risk is based on the probability of technology development success versus the impact of the technology on the system

- Technology development probability of failure is similar to any project. Should have defined WBS, requirements, schedule, cost, etc.

- Expert opinion is used for assessment; AHP is one method to obtain and integrate the opinions.

- Expert opinion or systems analysis can be used to define the impact of the technology on the system.

- For total Agency impact, future enterprise missions need to be prioritized to assess technology global impact and risk. 